Revista Brasileira de Agricultura Irrigada v.11, nº.8, p. 2206 - 2216, 2017

ISSN 1982-7679 (On-line)

Fortaleza, CE, INOVAGRI - http://www.inovagri.org.br

DOI: $10.7127 /$ rbai.v11n800717

Protocolo 717.17 - 10/07/2017 Aprovado em 16/09/2017

\title{
ALTERAÇÃO QUÍMICA DO SOLO CULTIVADO COM FEIJÃO CAUPI SOB SALINIDADE E DOIS REGIMES HÍDRICOS
}

João Valdenor Pereira Filho ${ }^{1}$, Francisco Marcus Lima Bezerra ${ }^{2}$, Tiago Cavalcante da Silva $^{3}$, Carmem Cristina Mareco de Sousa Pereira ${ }^{4}$, Keivia Lino Chagas ${ }^{5}$

\section{RESUMO}

Objetivou-se analisar as alterações químicas de um Argissolo Vermelho Amarelo cultivado com duas cultivares de feijão-caupi irrigado com água de salinidade crescente e dois regimes de irrigação. $\mathrm{O}$ experimento foi conduzido em vasos, a céu aberto em delineamento de blocos ao acaso utilizando o fatorial $2 \times 2 \times 5$, em parcelas subsubdivididas, referentes as lâminas de irrigação correspondentes a 100 e $50 \%$ da evapotranspiração potencial da cultura - ETpc, duas cultivares de feijão caupi (Vigna unguiculata L. Walp), Epace 10 e BRS Itaim e os níveis de salinidade das águas de irrigação de 0,$95 ; 2,45 ; 3,95 ; 5,45$ e $6,95 \mathrm{dS} \mathrm{m}^{-1}$. As parcelas corresponderam as lâminas de irrigação e as subparcelas à combinação de cada cultivar com cada condutividade elétrica da água de cada água de irrigação. Aos 70 dias após a semeadura avaliaram-se a condutividade elétrica do extrato de saturação solo e os valores de $\mathrm{pH}$, cálcio, magnésio, potássio e sódio do solo. A redução da lâmina de irrigação de 100 para 50\% ETpc elevou em $77,7 \%$ o teor de potássio do solo. O aumento da concentração de sais na água de irrigação reduziu o $\mathrm{pH}$ da solução do solo, mas provocou aumento da salinidade e do teor de potássio solo. Os teores de cálcio, magnésio e sódio não foram influenciados pelo aumento da salinidade das águas e nem pela redução da lâmina de irrigação de 100 para $50 \%$ ETpc.

Palavras-chave: Irrigação. Salinidade do solo e da água. Vigna unguiculata L.

\section{CHEMICAL ALTERATION OF SOIL CULTIVATED WITH CAUPI BEAN UNDER SALINITY AND TWO WATER SYSTEMS}

\author{
ABSTRACT

\footnotetext{
${ }^{1}$ Doutor em Engenharia Agrícola, Bolsista PNPD, UFC, e-mail: joao_valdenor@hotmail.com

${ }^{2}$ Doutor em Agronomia, Professor da UFC, e-mail: mbezerra@ufc.br;

${ }^{3}$ Mestrando em Ciência do Solo, UFC, e-mail: tiago.cavalcante@ hotmail.com

${ }^{4}$ Doutora em Engenharia Agrícola, UFRPE, e-mail: crismareco@ hotmail.com

${ }^{5}$ Doutoranda em Engenharia Agrícola, UFC, e-mail: kei-via@hotmail.com
} 
The objective of this work was to analyze the chemical alterations of a Red Yellow Argisol cultivated by two cultivars of cowpea irrigated with water of increasing salinity and two irrigation regimes. The experiment was conducted in pots, open air in randomized block design using factorial $2 \times(2 \times 5)$, in subdivided plots, referring to irrigation slides corresponding to 100 and $50 \%$ of the potential evapotranspiration of the crop - ETpc, two cultivars of cowpea (Vigna unguiculata L. Walp), Epace 10 and BRS Itaim and irrigation water salinity levels of $0.95 ; 2.45 ; 3.95 ; 5.45$ and $6.95 \mathrm{dS} \mathrm{m}^{-1}$. The plots corresponded to the irrigation slides and the subplots to the combination of each cultivar with each electrical conductivity of the water of each water irrigation. At 70 days after sowing, the electrical conductivity of the soil saturation extract and $\mathrm{pH}$, calcium, magnesium, potassium and sodium values of the soil were evaluated. The reduction of the irrigation depth from 100 to $50 \%$ ETpc increased by $77,7 \%$ the potassium content of the soil. The increase in salt concentration in the irrigation water reduced the $\mathrm{pH}$ of the soil solution, but caused an increase in salinity and soil potassium content. Calcium, magnesium and sodium contents were not influenced by the increase of the salinity of the waters nor by the reduction of the irrigation depth from 100 to $50 \%$ ETpc.

Keywords: Irrigation. Salinity of soil and water. Vigna unguiculata L.

\section{INTRODUÇÃO}

De acordo com Carvalho et al. (2013), a irrigação garante a viabilidade econômica do cultivo das leguminosas, principalmente em regiões onde há baixa disponibilidade hídrica. No caso do Nordeste, com o uso dessa tecnologia, as produtividades obtidas têm sido viáveis, mas o uso de águas restritivas quanto aos sais, associado ao manejo do sistema solo-água-planta, e à deficiência do sistema de drenagem têm causado sérios problemas de salinidade em áreas irrigadas (PEDROTTI et al., 2015).

A concentração elevada de sais no solo, condiciona um ambiente hostil à maioria das plantas, prejudicando o comportamento vegetativo, pela ação indireta sobre o potencial osmótico e direta pelos efeitos dos íons especificamente tóxicos (FREIRE et al., 2010). Assim, a inconveniência da sensibilidade das culturas aos sais da água e do solo, evidencia a necessidade de pesquisas que tenham como meta a obtenção de tecnologias viáveis para os produtores e que possam minimizar os efeitos deletérios da salinidade às plantas, vez que é quase inevitável a utilização de águas salinas na agricultura em regiões semiáridas (DIAS et al., 2015).
O feijão-caupi Vigna unguiculata (L.) Walp., além da grande expressividade econômica, é uma eficiente fonte de proteínas e carboidratos que torna uma cultura importante na dieta humana, no entanto, seu potencial genético ainda é pouco explorado. Pesquisas citam que muitas cultivares de feijão-caupi são adaptadas às regiões semiáridas do nordeste brasileiro, com produção de grãos em cultivos de sequeiros. Mesmo com essa adaptabilidade, o feijãocaupi é uma cultura moderadamente tolerante à salinidade, tolerando condutividade elétrica da água de irrigação de até $3,3 \mathrm{dS} \mathrm{m}^{-1}$, a partir da qual se verifica queda na produtividade (PRAZERES et al., 2015).

Em estudo desenvolvido por Ramos et al. (2014), avaliando a produtividade de grãos verdes, os componentes de produção e a eficiência do uso da água do feijão-caupi, sob regimes hídricos, constataram que a produtividade de grãos verdes e vagens verdes, o número de vagens verdes por planta, o comprimento médio das vagens verdes e o número de grãos verdes por vagem diminuem com a redução das lâminas de irrigação. Pesquisa publicada por NASCIMENTO et al. (2004), estudando o efeito da variação de níveis de água disponível no solo (40\%; 60\%; 80\% e 100\%), sobre o crescimento e a produtividade de 
vagens e grãos verdes do feijão-caupi cultivar IPA 206, em Areia, Paraíba, verificaram que os diferentes níveis de água disponível no solo influenciaram significativamente no crescimento das plantas e na produtividade de grãos verdes do feijão-caupi.

Objetivou-se com este trabalho avaliar as alterações químicas de um solo cultivado por duas cultivares de feijão-caupi sob níveis de salinidade da água de irrigação associados a dois regimes hídricos.

\section{MATERIAL E MÉTODOS}

$\mathrm{O}$ experimento foi conduzido na área experimental da Estação Agrometeorológica do Departamento de Engenharia Agrícola, pertencente ao Centro de Ciências Agrárias da Universidade Federal do Ceará (UFC), no município de Fortaleza, estado do Ceará, com coordenadas geográficas $03^{\circ} 45^{\prime} \mathrm{S}, 38^{\circ} 33^{\prime} \mathrm{W}$, altitude média $19 \mathrm{~m}$, no período de agosto de 2014 a dezembro de 2014. O clima da região, segundo a classificação de Köppen, é do tipo Aw', tropical chuvoso, com temperaturas elevadas e com estação chuvosa predominante no outono.

Utilizou-se duas cultivares de feijão de corda (Epace 10 e BRS Itaim), produzidas pela Empresa de Pesquisa Agropecuária do Ceará e Embrapa Meio Norte. A área útil total ocupada com o feijão-caupi foi de 24,0 $\mathrm{x} 3,0 \mathrm{~m}=72,0 \mathrm{~m}^{2}$, onde foram instalados os 180 vasos plásticos, que possuíam volume de 15 litros, cada.

Cada parcela, individualmente, ocupava uma área útil de $12,0 \mathrm{~m}^{2}$, sendo composta por 30 vasos, distribuídos em cinco linhas de plantio. Já as subparcelas ocuparam, isoladamente, uma área útil de $2,4 \mathrm{~m}^{2}$, sendo composta de seis vasos distribuídos por linha de plantio. E as subsubparcelas, com três vasos cada, ocuparam uma área útil de $1,2 \mathrm{~m}^{2}$.

Inicialmente, antes da deposição do solo utilizado como substrato para o cultivo das plantas, depositou-se, ao fundo dos vasos, uma camada de brita $\mathrm{n}^{\mathrm{o}} 1$, para facilitar a livre drenagem do excedente hídrico, a qual, sequencialmente, foi preenchido revestida por uma manta, para evitar possíveis perdas de solo. Os vasos de material plástico flexível, com capacidade volumétrica de 15 L, possuíam orifícios na extremidade inferior, que objetivavam promover a remoção dos eventuais excessos de água.

Como substrato para o cultivo das plantas, foi utilizado uma amostra de Argiloso Vermelho-Amarelo, textura franco arenoso (EMBRAPA, 2013), oriunda de uma área com vegetação nativa, localizada próximo a área experimental da Estação Agrometeorológica, coletadas na profundidade de $0-0,20 \mathrm{~m}$, cujos resultados dos atributos físico hídricos e químicos estão expostos na Tabela 1 e 2 , respectivamente.

Tabela 1 - Atributos físico hídricos do solo utilizado como substrato para o cultivo das plantas no experimento. Estação Agrometeorológica, Fortaleza, Ceará, 2016

\begin{tabular}{|c|c|c|c|c|c|c|c|c|}
\hline \multirow{2}{*}{ Camada } & \multicolumn{3}{|c|}{$\begin{array}{l}\text { Composição } \\
\text { granulométrica }\end{array}$} & \multirow{2}{*}{$\begin{array}{l}\text { Classe } \\
\text { textural }\end{array}$} & \multicolumn{2}{|c|}{ Densidade } & \multicolumn{2}{|c|}{ Umidade } \\
\hline & Areia & Silte & Argila & & Solo & Partículas & $\begin{array}{c}33 \\
\text { Kра }\end{array}$ & $\begin{array}{c}1.500 \\
\text { Kpa }\end{array}$ \\
\hline (m) & \multicolumn{3}{|c|}{$\left(\mathrm{g} \mathrm{kg}^{-1}\right)$} & $(-)$ & \multicolumn{2}{|c|}{$\left(\mathrm{g} \mathrm{cm}^{-3}\right)$} & \multicolumn{2}{|c|}{$(\mathrm{g} / 100 \mathrm{~g})$} \\
\hline $0-0,20$ & 785 & 76 & 139 & $\begin{array}{l}\text { Franco } \\
\text { arenoso }\end{array}$ & 1,49 & 2,55 & 7,51 & 4,77 \\
\hline
\end{tabular}

Tabela 2 - Atributos químicos do solo utilizado como substrato para o cultivo das plantas no experimento. Estação Agrometeorológica, Fortaleza, Ceará, $2016^{1}$

\begin{tabular}{|c|c|c|c|c|c|c|c|c|}
\hline \multirow{2}{*}{ Camada } & $\mathrm{pH}$ & \multirow{2}{*}{$\mathrm{CE}$} & \multicolumn{6}{|c|}{ Complexo sortivo } \\
\hline & (Água) & & $\mathrm{Ca}^{2+}$ & $\mathrm{Mg}^{2+}$ & $\mathrm{K}^{+}$ & $\mathrm{Na}^{+}$ & $\mathrm{H}^{+}+\mathrm{Al}^{3+}$ & $\mathrm{Al}^{3+}$ \\
\hline (m) & $(-)$ & $\left(\mathrm{dS} \mathrm{m} \mathrm{m}^{-1}\right)$ & \multicolumn{6}{|c|}{$\left(\mathrm{cmol}_{\mathrm{c}} \mathrm{kg}^{-1}\right)$} \\
\hline $0-0,20$ & 4,2 & 0,17 & 0,70 & 0,60 & 0,15 & 0,06 & 3,14 & 0,95 \\
\hline
\end{tabular}




\begin{tabular}{ccccccc}
\hline Camada & $\mathrm{S}$ & $\mathrm{T}$ & $\mathrm{V}$ & $\mathrm{PST}$ & M.O. & P Assimilável \\
\hline$(\mathrm{m})$ & $\left(\mathrm{cmol}_{\mathrm{c}} \mathrm{kg}^{-1}\right)$ & & $(\%)$ & & $\left(\mathrm{g} \mathrm{kg}^{-1}\right)$ & $\left(\mathrm{mg} \mathrm{kg}^{-1}\right)$ \\
\hline $0-0,20$ & 1,5 & 4,6 & 33 & 1,0 & 9,41 & 3 \\
\hline
\end{tabular}

${ }^{1} \mathrm{pH}$ - potencial hidrogeniônico (água - 1:2,5), CE - condutividade elétrica do extrato de saturação do solo (CE - água - 1:2,5); S - soma de bases; T - capacidade de troca de cátions; V - saturação por bases; PST - percentagem de sódio trocável; M.O. - matéria orgânica.

$\mathrm{Na}$ sequência, procedeu-se com o preenchimento dos vasos, com um composto orgânico de húmus de minhoca na proporção de $2: 1$.

A aplicação dos fertilizantes químicos da fundação foi realizada, baseados na análise de solo e exigências nutricionais da cultura obedecendo às prescrições de Aquino et al. (1993). As quantidades necessárias de macronutrientes foram às seguintes: $20,00 \mathrm{~kg}$ $\mathrm{ha}^{-1}$ de nitrogênio $(\mathrm{N}), 80,00 \mathrm{~kg} \mathrm{ha}^{-1} \mathrm{de}$ fósforo $(\mathrm{P})$ e $30,00 \mathrm{~kg} \mathrm{ha}^{-1}$ de potássio $(\mathrm{K})$, sendo utilizados como fontes a ureia, o fosfato monoamônio (MAP) e o cloreto de potássio, respectivamente. No entanto, por ocasião do plantio, aplicaram-se em sua totalidade, o equivalente a 15 e $5 \mathrm{~g} \mathrm{vaso}^{-1}$, apenas as quantidades referentes ao fosfato monoamônio (MAP) e o cloreto de potássio. A aplicação da fonte ureia foi fracionada igualitariamente, e aplicado aos 15 e 30 DAP em cobertura, sendo a quantidade correspondente a $5 \mathrm{~g} \mathrm{vaso}^{-1}$.

Com o intuito de corrigir e, ou, evitar possíveis deficiências de micronutrientes, aplicou-se ainda, por ocasião do plantio, o equivalente a $10 \mathrm{~g}$ da formulação comercial FTE BR 12 [Cálcio (Ca): 7,1\%; Enxofre (S): $5,7 \%$; Boro (B): $1,8 \%$; Cobre $(\mathrm{Cu}): 0,8 \%$;
Manganês (Mn): 2,0\%; Molibdênio (Mo): 0,1\% e Zinco (Zn): 9,0\%].

O plantio foi feito com três ou quatro sementes por vaso, aos 7 dias após a semeadura (DAS) e aos 10 DAS efetuou-se o desbaste deixando-se as duas plantas mais vigorosas por vaso.

O experimento foi conduzido em vasos, a pleno sol em delineamento de blocos ao acaso utilizando o fatorial $2 \times(2 \times 5)$, em parcelas subdivididas, referentes as lâminas de irrigação correspondentes a 100 e $50 \%$ da evapotranspiração potencial da cultura ETpc, duas cultivares de feijão caupi (Vigna unguiculata L. Walp), Epace 10 e BRS Itaim e os níveis de salinidade das águas de irrigação de 0,$95 ; 2,45 ; 3,95 ; 5,45$ e 6,95 dS $\mathrm{m}^{-1}$.

A água utilizada para abastecimento do sistema de irrigação era proveniente de um poço freático, pertencente à Estação Agrometeorológica da Universidade Federal do Ceará. O resultado da análise da qualidade da água para fins de irrigação está apresentado na Tabela 3. Pelo resultado, constatou-se que a água em questão apresenta alta salinidade $\left(\mathrm{C}_{3}\right)$ e baixo conteúdo de sódio $\left(\mathrm{S}_{1}\right)$.

Tabela 3 - Resultados da análise de qualidade da água para fins de irrigação. Estação Agrometeorológica, Fortaleza, Ceará, 2016

\begin{tabular}{|c|c|c|c|c|c|c|c|c|c|}
\hline \multicolumn{5}{|c|}{ Cátions $\left(\mathrm{mmol}_{\mathrm{c}} \mathrm{L}^{-1}\right)$} & \multicolumn{5}{|c|}{ Ânions $\left(\mathrm{mmol}_{\mathrm{c}} \mathrm{L}^{-1}\right)$} \\
\hline $\mathrm{Ca}^{2+}$ & $\mathrm{Mg}^{2+}$ & $\mathrm{Na}^{+}$ & $\mathrm{K}^{+}$ & $\Sigma$ & $\mathrm{Cl}^{-}$ & $\mathrm{SO}_{4}^{2-}$ & $\mathrm{HCO}_{3}^{-}$ & $\mathrm{CO}_{3}^{2-}$ & $\Sigma$ \\
\hline 1,3 & 3,1 & 4,5 & 0,4 & 9,3 & 5,2 & - & 4,3 & - & 9,5 \\
\hline \multicolumn{2}{|c|}{$\mathrm{CE}\left(\mathrm{dS} \mathrm{m^{-1 }}\right)$} & \multicolumn{2}{|c|}{ RAS } & \multicolumn{2}{|c|}{$\mathrm{pH}$} & \multicolumn{2}{|c|}{ Sólidos dissolvidos $\left(\mathrm{mg} \mathrm{L}^{-1}\right)$} & \multicolumn{2}{|c|}{ Classificação } \\
\hline \multicolumn{2}{|c|}{0,95} & \multicolumn{2}{|c|}{3,05} & \multicolumn{2}{|c|}{8,0} & \multicolumn{2}{|c|}{950} & \multicolumn{2}{|c|}{$\mathrm{C}_{3} \mathrm{~S}_{1}$} \\
\hline
\end{tabular}

O sistema de irrigação adotado foi por gotejamento, utilizando-se emissores com vazão de $10 \quad \mathrm{~L} \mathrm{~h}^{-1}$, os quais foram previamente avaliados em campo, sob condições normais de operação, conforme a metodologia descrita por Keller e Karmelli
(1975). Na ocasião, o sistema de irrigação foi testado adotando-se uma vazão nominal de 2 $\mathrm{L} \mathrm{h}^{-1}$, com coeficiente de uniformidade de distribuição (CUD) de $90 \%$.

$\mathrm{O}$ método de manejo de irrigação adotado foi via clima. Para a determinação da 
evapotranspiração potencial da cultura ETpc, adotou-se a metodologia proposta por Bernardo et al. (2008), onde, primeiramente, procedeu-se a estimativa da evapotranspiração de referência (ETo).

Para a determinação da estimativa diária da evapotranspiração de referência ETo foi utilizado um tanque evaporímetro do tipo Classe A, localizado nas imediações da área experimental, pertencente à estação Agrometeorológica da Universidade Federal do Ceará, nos quais as leituras eram aferidas diariamente às $9 \mathrm{~h}$.

A evapotranspiração de referência
(ETo) foi estimada através da equação 1 (BERNARDO et al., 2008):

$$
E T o=E C A . K t
$$

em que: ETo - Evapotranspiração de referência estimada através do Tanque Classe "A" (mm); ECA - Evaporação medida através do Tanque Classe "A" (mm); Kt Coeficiente de ajuste do tanque (adimensional).

Para a obtenção do (Kt), foi utilizada a equação proposta por SNYDER (1992), apresentada abaixo:

$$
K t=0,482+0,024 \ln (F)-0,000376 U+0,0045 U R
$$

em que: F - Distância do centro do tanque ao limite da bordadura (tanque circundado por grama a $10 \mathrm{~m}$ ); U - Velocidade média do vento a $2 \mathrm{~m}$ de altura $\left(\mathrm{km} \mathrm{dia}^{-1}\right)$; UR Umidade relativa média do ar (\%).

Os dados climáticos necessários para o cálculo do $(\mathrm{Kt})$ foram obtidos mediante a média aritmética dos últimos cinco anos, para os meses nos quais o experimento foi conduzido, sendo coletados em uma estação meteorológica automatizada, localizada nas imediações da área experimental.

A evapotranspiração potencial da cultura foi estimada (ETpc), através da equação 3 , mediante a multiplicação da evapotranspiração de referência e o coeficiente da cultura $(\mathrm{Kc})$, segundo Bernardo et al. (2008).

$$
E T p c=E T o . K c
$$

em que: ETpc - Evapotranspiração potencial da cultura (mm); ETo - Evapotranspiração de referência estimada através do Tanque Classe "A" (mm); Kc - Coeficientes de cultivo.

Foi adotado os coeficientes de cultivo (Kc) igual a 0,70 (até 12 dias após o plantio, DAP); 0,81 (de 13 a 33 DAP); 1,2 (de 34 a 54 DAP) e 0,77 (de 55 DAP ao final do ciclo), conforme o proposto por Sousa et al. (2005).
Já o tempo de irrigação, utilizado foi calculado a partir da equação 4 :

$$
T_{I}=\frac{E T p c \cdot A_{v}}{C U D \cdot q_{g}}
$$

em que: $\mathrm{T}_{\mathrm{I}}$ - Tempo de irrigação (h); ETpc Evapotranspiração potencial da cultura $(\mathrm{mm}) ; \mathrm{A}_{\mathrm{v}}$ - Área do vaso $\left(\mathrm{m}^{2}\right)\left(0,0706 \mathrm{~m}^{2}\right)$; CUD - Coeficiente de uniformidade de distribuição de água do sistema de irrigação (Valor obtido em avaliação, CUD $=0,90$ ); $\mathrm{q}_{\mathrm{g}}$ - Vazão do gotejador, $\mathrm{L} \mathrm{h}^{-1}\left(\mathrm{q}_{\mathrm{g}}=2 \mathrm{~L} \mathrm{~h}^{-1}\right)$;

Após o plantio das sementes de feijãocaupi, o experimento foi irrigado diariamente com uma lâmina equivalente a $100 \%$ da evapotranspiração potencial da cultura ETpc, a fim de garantir o estabelecimento inicial da cultura, até o início da diferenciação dos tratamentos, que se deu aos 10 dias após o plantio - DAP, mediante a variação dos níveis de salinidade da água de irrigação.

Após a imposição dos tratamentos de salinidade da água de irrigação o experimento passou a ser irrigado com uma frequência equivalente há dois dias consecutivos.

A água salina utilizada nas irrigações era proveniente de um poço freático, sendo armazenada em reservatórios com capacidade de 310 L. A quantidade dos sais 
$\mathrm{NaCl}, \mathrm{CaCl}_{2} \cdot 2 \mathrm{H}_{2} \mathrm{O}, \mathrm{MgCl}_{2} \cdot 6 \mathrm{H}_{2} \mathrm{O}$, utilizadas no preparo das águas de irrigação foi determinada de forma a se obter a CEa desejada na proporção 7:2:1 obedecendo a relação entre $\mathrm{CEa}$ e sua concentração $\left(\mathrm{mmol}_{\mathrm{c}}\right.$ $\mathrm{L}^{-1}=\mathrm{CE} \times 10$ ), conforme (RHOADES et al., 2000).

Ao final do ciclo da cultura, 70 dias após a semeadura - DAS, foram coletadas amostras simples de solo, de cada unidade experimental. O material foi acondicionado em sacos de polietileno etiquetados e enviado para o Laboratório de Solos e Água para Irrigação pertencente ao Instituto Federal de Educação, Ciência e Tecnologia do Ceará, Campus Sobral. Os atributos químicos do solo analisados foram: Condutividade elétrica do solo, $\mathrm{pH}$ da solução do solo e teores de cálcio, magnésio, potássio e sódio no solo.

Os dados das variáveis avaliadas foram submetidos à análise de variância pelo teste $\mathrm{F}$ a 1 e 5\% de probabilidade. Quando verificado efeito significativo na análise de variância, os dados obtidos nos diferentes tratamentos foram submetidos ao estudo de regressão, buscando-se optar por aquele modelo matemático que melhor se ajustou aos dados do experimento, tendo em vista os coeficientes de determinação $\mathrm{R}^{2}$, o valor do teste $\mathrm{F}$ da análise de variância e os aspectos relacionados ao comportamento biológico dos processos, utilizando-se, para isso, o software para análises estatísticas Assistat 7.7 beta, auxiliado pelo software Microsoft Office Excel 2007.

\section{RESULTADOS E DISCUSSÃO}

Verifica-se a partir da análise de variância que a condutividade elétrica do solo foi influenciada significativamente pelos fatores regime hídrico $(\mathrm{p} \leq 0,05)$, salinidade $(p \leq 0,01)$ e cultivares $(p \leq 0,05)$; já o $p H$, apresentou significância apenas para o fator salinidade $(\mathrm{p} \leq 0,01)$; o Potássio apresentou influência significa para o fator regime hídrico $(\mathrm{p} \leq 0,01)$, enquanto o Cálcio, Magnésio, e Sódio não foram influenciados por nenhum dos fatores avaliados. Os atributos químicos do solo avaliados não apresentaram influência significativa na interação tripla entre os fatores estudados (Tabela 4).

Tabela 4 - Resumo das análises das variâncias para os dados de condutividade elétrica, pH, fósforo, potássio, cálcio, magnésio e sódio do solo cultivado com feijão-caupi sob diferentes níveis de salinidade da água de irrigação e regimes hídricos.

\begin{tabular}{lccccccc}
\hline \multirow{2}{*}{ FV } & \multirow{2}{*}{$\mathrm{GL}$} & \multicolumn{6}{c}{ Quadrados Médios } \\
\cline { 3 - 8 } & & $\mathrm{CE}_{\mathrm{es}}$ & $\mathrm{pH}$ & $\mathrm{Ca}$ & $\mathrm{Mg}$ & $\mathrm{K}$ & $\mathrm{Na}$ \\
\hline Blocos & 2 & $1,88^{\text {ns }}$ & $0,02^{\text {ns }}$ & $2,81^{*}$ & $2445,3^{\text {ns }}$ & $0,11^{\text {ns }}$ & $67,96^{\text {ns }}$ \\
Regime Hídrico (A) & 1 & $2,91^{*}$ & $0,34^{\text {ns }}$ & $1848,15^{\text {ns }}$ & $6594,0^{\text {ns }}$ & $1,22^{* *}$ & $0,08^{\text {ns }}$ \\
Resíduo - A & 2 & 0,11 & 0,05 & 523,95 & 1264,2 & 0,01 & 14,11 \\
\hline Parcelas & 5 & & & & & & \\
\hline Salinidade (B) & 4 & $10,19^{* *}$ & $0,44^{* *}$ & $553,19^{\text {ns }}$ & $611,5^{\text {ns }}$ & $0,11^{\text {ns }}$ & $50,38^{\text {ns }}$ \\
Inter. - A x B & 4 & $0,51^{\text {ns }}$ & $0,05^{\text {ns }}$ & $308,02^{\text {ns }}$ & $768,9^{\text {ns }}$ & $0,15^{\text {ns }}$ & $16,74^{\text {ns }}$ \\
Resíduo - B & 16 & 0,94 & 0,06 & 186,01 & 715,4 & 0,08 & 18,16 \\
\hline Subparcelas & 29 & & & & & & \\
\hline Cultivares (C) & 1 & $5,08^{*}$ & $0,06^{\text {ns }}$ & $183,75^{\text {ns }}$ & $252,1^{\text {ns }}$ & $0,01^{\text {ns }}$ & $4,09^{\text {ns }}$ \\
Inter. - A x C & 1 & $0,38^{\text {ns }}$ & $0,01^{\text {ns }}$ & $114,82^{\text {ns }}$ & $36,8^{\text {ns }}$ & $0,02^{\text {ns }}$ & $1,24^{\text {ns }}$ \\
Inter. - B x C & 4 & $0,58^{\text {ns }}$ & $0,17^{\text {ns }}$ & $60,62^{\text {ns }}$ & $152,8^{\text {ns }}$ & $0,08^{\text {ns }}$ & $21,32^{\text {ns }}$ \\
Inter. - A x B x C & 4 & $1,52^{\text {ns }}$ & $0,03^{\text {ns }}$ & $87,52^{\text {ns }}$ & $108,3^{\text {ns }}$ & $0,07^{\text {ns }}$ & $18,13^{\text {ns }}$ \\
Resíduo - C & 20 & 0,71 & 0,09 & 196,31 & 418,6 & 0,08 & 9,97 \\
\hline Total & 59 & \multicolumn{7}{c}{} & & & \\
\hline C.V - A (\%) & & 9,95 & 3,21 & 34,05 & 60,87 & 16,42 & 63,03 \\
C.V - B (\%) & & 30,25 & 3,41 & 20,29 & 45,79 & 57,46 & 71,49 \\
C.V - C $(\%)$ & & 26,23 & 4,31 & 20,84 & 35,03 & 58,83 & 52,97 \\
\hline
\end{tabular}

${ }^{1}\left({ }^{*}\right)$, significativo a $5 \%$ de probabilidade; $\left({ }^{* *}\right)$, significativo a $1 \%$ de probabilidade, $\left({ }^{\mathrm{n}}\right)$, não significativo pelo teste $\mathrm{F}$. 
Na Figura 1a observa-se os valores médios da condutividade elétrica do solo sob os regimes hídricos de $50 \%$ e $100 \%$ da ETpc. O maior valor de condutividade elétrica $(3,44$ $\mathrm{dS} \mathrm{m}^{-1}$ ) foi observado no tratamento que recebeu um regime de irrigação de $50 \%$ da ETpc. Pode-se inferir que tal fato ocorreu devido à retenção dos sais da água de irrigação, uma vez que em tal condição, não foram observadas a lixiviação dos sais por meio da água percolada nos vasos. Resultados semelhantes são apresentados por Ferreira et al. (2006) ao constatarem aumento da condutividade elétrica do solo com a diminuição da fração de lixiviação. (a)

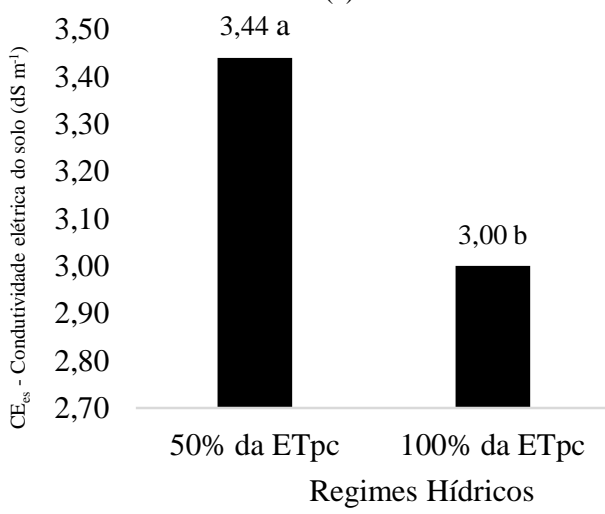

(b)

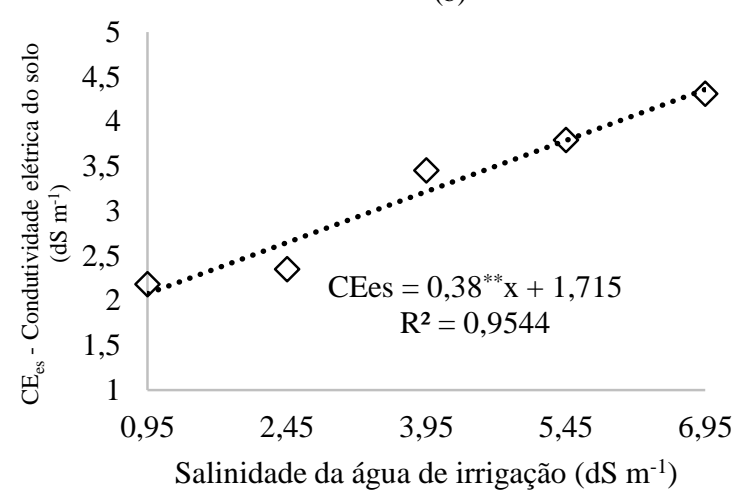

Figura 1. (a) Condutividade elétrica do solo $\left(\mathrm{CE}_{\mathrm{es}}\right)$ sob regimes hídricos de $50 \%$ e $100 \%$ da ETpc; (b) Condutividade elétrica do solo $\left(\mathrm{CE}_{\text {es }}\right)$ em função de níveis de salinidade da água de irrigação.

Holanda Filho et al. (2011) estudando os atributos químicos do solo, Latossolo Amarelo Eutrófico, irrigado com água salina em diferentes lâminas aplicadas (110, 120, 130, 140 e $150 \%$ da ETpc), constataram aumento da salinidade na profundidade de 0 $0,20 \mathrm{~m}$, evidenciando que as lâminas de irrigação superiores à lâmina de evapotranspiração da cultura não foram suficientes para lixiviação dos sais.

Rhoades et al. (2000) alertam que a diminuição do potencial osmótico associada a frações de lixiviação pequenas e ao uso de águas de irrigação salinas, torna-se especialmente perigoso, porque o nível de "estresse crítico" do potencial total será alcançado mais rapidamente, principalmente para culturas sensíveis à salinidade.

O resultado obtido no regime hídrico de $100 \%$ da ETpc deu-se, pela maior lixiviação sobre o acúmulo de sais do solo. Pois, de acordo com Carvalho et al. (2012); Assis Júnior et al. (2007); Wilson et al. (2006), o excedente da água de irrigação lixivia o excesso de sais no perfil do solo, resultando em menor efeito da salinidade no ambiente radicular, o que favorece o crescimento e o desenvolvimento da cultura.

A condutividade elétrica do solo aumentou significativamente com o teor salino da água de irrigação, sendo o modelo liner crescente o que melhor representou os dados desta variável $\left(\mathrm{R}^{2}=0,9544\right)$. Os valores estimados para a CEes no tratamento de maior nível salino foi em média 2 vezes maior do que o valor encontrado no menor nível salino (Figura 1b). Resultados semelhantes são apresentados por Silva et al. (2011), Gonçalves et al. (2011) e Garcia et al. (2008), ao verificarem resposta linear crescente da condutividade elétrica do solo com o aumento da concentração de sais na água de irrigação.

Vale ressaltar, que o acúmulo de sais no solo provoca a redução dos fatores morfológicos da planta, além de afetar o desenvolvimento das raízes da cultura como afirma Silva et al. (2013), em estudos sobre o ajustamento osmótico da cultura da beterraba.

Entre as cultivares avaliadas, observase na Figura 2 que os valores da 
condutividade elétrica do solo, nos vasos cultivados com a Epace 10, apresentaram maiores valores desta variável $\left(3,51 \mathrm{dS} \mathrm{m}^{-1}\right)$. Sobre tal resultado pode-se inferir que a cultivar Epace 10, possivelmente, tolera a maior concentração de sais no solo do que a cultivar BRS Itaim, que demonstra assim ser mais sensível. Resultados semelhantes aos reportados por Pedrotti et al. (2015) ao mencionar que a sensibilidade à existência de maiores ou menores teores de sais no solo é uma característica peculiar até entre genótipos de uma mesma espécie.
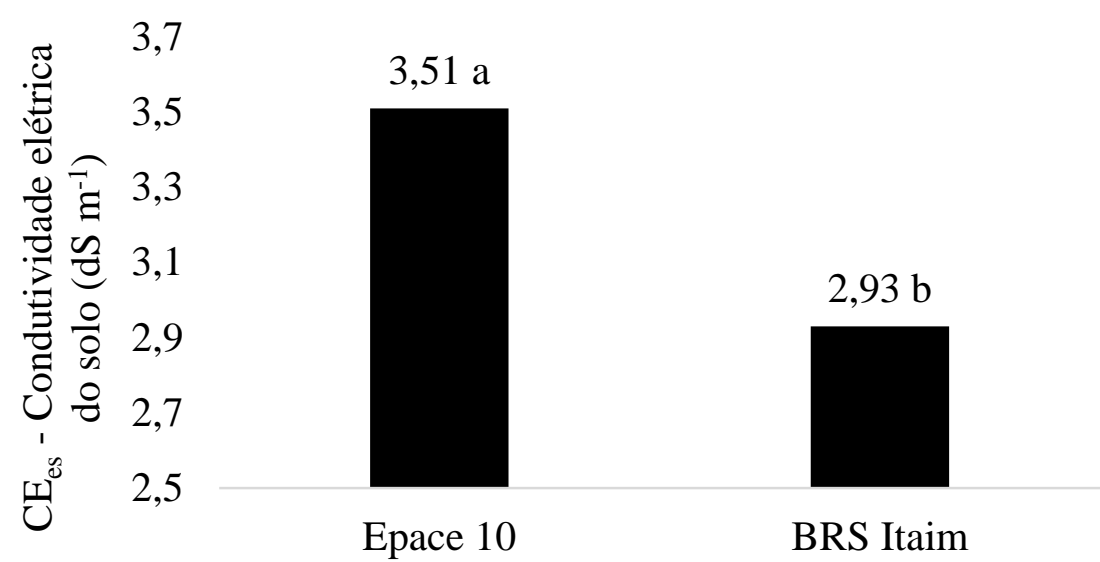

\section{Cultivares}

Figura 2. Condutividade elétrica do solo $\left(\mathrm{CE}_{\mathrm{es}}\right)$ associado ao manejo da irrigação em diferentes níveis de salinidade e regimes hídricos das cultivares Epace 10 e BRS Itaim.

Algumas espécies vegetais apresentam mecanismos que lhes permitem sobreviver em ambientes altamente salinos. A sobrevivência nestes ambientes pode resultar em processos adaptativos que envolvem absorção, transporte e distribuição de íons em vários órgãos da planta (FARIAS et al., 2009). Umas das estratégias utilizadas pelas plantas é a extrusão do $\mathrm{Na}^{+}$para a solução do solo retirando o cátion da planta e a expulsão do $\mathrm{Na}^{+}$de alguns tecidos, especialmente o xilema, como forma de evitar o acúmulo do cátion no limbo foliar, minimizando os efeitos deletérios da salinidade sobre o metabolismo foliar, em especial sobre o processo fotossintético (MUNNS et al., 2002).

Na Figura 3 observa-se que o potencial hidrogeniônico $(\mathrm{pH})$ diminuiu com o teor salino da água de irrigação, sendo o modelo liner decrescente o que melhor representou os dados desta variável $\left(\mathrm{R}^{2}=0,8696\right)$. Resultados semelhantes são apresentados por Dias et al. (2015) e Garcia et al. (2008) ao verificarem resposta linear decrescente do $\mathrm{pH}$ do solo com o aumento da concentração de sais na água de irrigação.

Uma possível explicação para a redução do potencial hidrogeniônico deve-se ao fato do aumento do conteúdo iônico da água de irrigação reduzir o pH da solução do solo, provavelmente em função do incremento de cloreto de cálcio $\left(\mathrm{CaCl}_{2}\right)$, ter induzido à substituição de ânions como carbonatos e bicarbonatos, promovendo a elevação da concentração de $\mathrm{H}^{+}$na solução do solo (Freitas et al., 2007). 


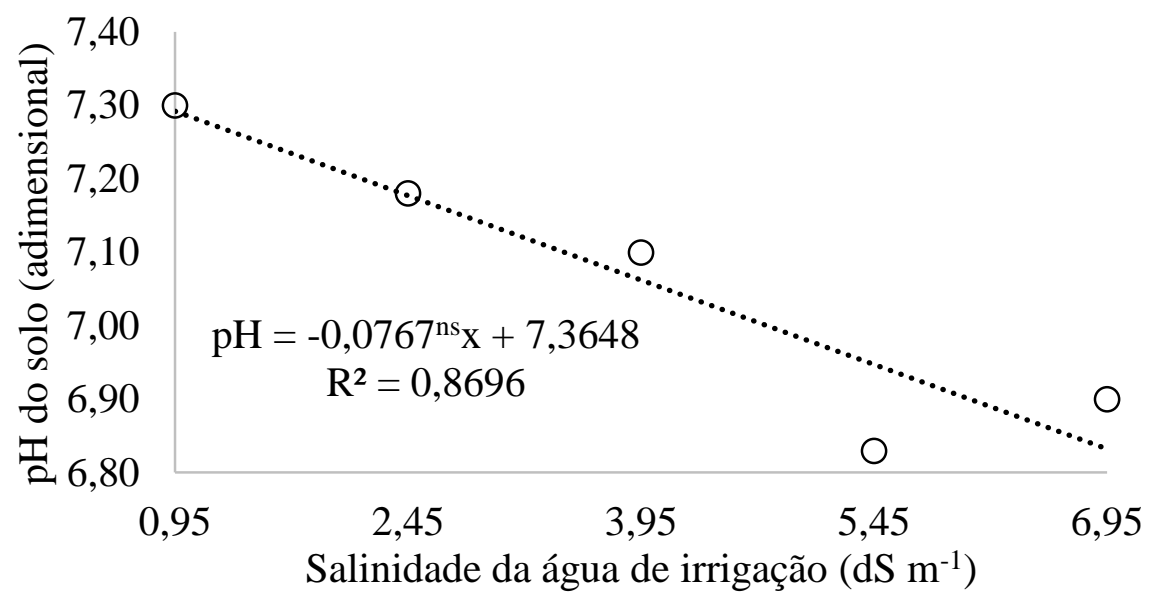

Figura 3. Potencial hidrogeniônico do solo $(\mathrm{pH})$ em função de níveis de salinidade da água de irrigação.

O teor de potássio apresentou maior média no tratamento sob lâmina de $50 \%$ da ETpc (Figura 4). Uma possível explicação para tal resultado deve-se ao fato de nestes tratamentos não ter ocorrido à percolação de água e consequente lixiviação deste elemento, já que no tratamento onde foi aplicado a lâmina de $100 \%$ da ETpc foi observado menores teores de potássio, exatamente devido a percolação de água que ocorria nos momentos de irrigação, o que possivelmente explicaria o comportamento deste elemento presente no solo em menores quantidades.

Outro aspecto importante a se destacar dá-se pela aplicação da adubação em cobertura do Cloreto de potássio, o que possivelmente associado ao manejo da irrigação, em destaque acima descrito, condicionou o solo a manter os maiores teores de potássio nos tratamentos onde não fora obtido a drenagem da água, permitindo assim a lixiviação do potássio.
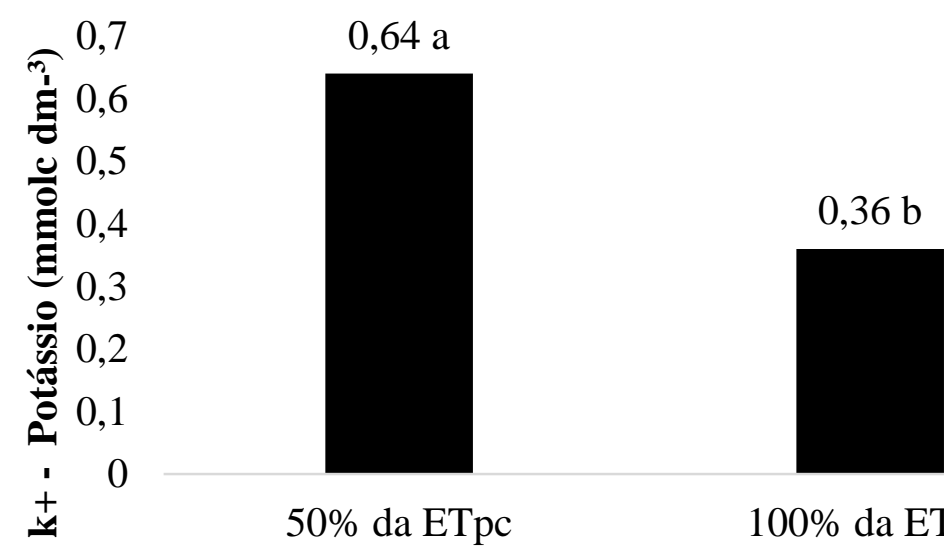

$100 \%$ da ETpc

\section{Regimes Hídricos}

Figura 4. Teores de Potássio (K) sob regimes hídricos de 50\% e 100\% da ETpc.

\section{CONCLUSÕES}

Os teores de cálcio, magnésio e sódio não foram influenciados pelo aumento da salinidade das águas e nem pela redução da lâmina de irrigação de 100 para $50 \%$ ETpc.

O regime hídrico de $50 \%$ da ETpc, propiciona maior condutividade elétrica e dos teores de potássio presentes no solo. 
O aumento da concentração de sais da água de irrigação reduziu o pH da solução do solo e aumentou a condutividade elétrica do solo.

\section{REFERÊNCIAS BIBLIOGRÁFICAS}

AQUINO, A. B. et al. Recomendações de adubação e calagem para o Estado do Ceará. Fortaleza: UFC, 1993. 247p.

BERNARDO, S.; SOARES, A. A; MANTOVANI, E. C. Manual de irrigação. 8.ed. Viçosa: Editora UFV, 2008. 625p.

CARVALHO, J. F. de; TSIMPHO, C. J.; SILVA, E. F de F. e; MEDEIROS, P. R. F. de; SANTOS, M. H. V. dos; SANTOS, A. N dos. Produção e biometria do milho verde irrigado com água salina sob frações de lixiviação. Revista Brasileira de Engenharia Agrícola e Ambiental, v. 16, n.4, p.368374, 2012.

DIAS, T. J.; FREIRE, J. L. de O.; CAVALCANTE, L. F.; NASCIMENTO, E. S. do; DANTAS, L. A.; DANTAS, M. M. de M. Atributos químicos do solo irrigado com águas salinas e uso de mitigadores do estresse salino no maracujazeiro amarelo. Revista principia, v. 1, n. 27, p. 1929, 2015.

$\begin{array}{lcr}\text { EMPRESA } & \text { BRASILEIRA } & \text { DE } \\ \text { PESQUISA } & \text { AGROPECUÁRIA } & - \\ \text { EMBRAPA. Centro } & \text { Nacional } & \text { de }\end{array}$
Pesquisa de Solos. Sistema Brasileiro de Classificação de Solos $2^{\text {a }}$ ed. Rio de Janeiro: Embrapa Solos, 2013, 306p.

FARIAS， S. G. G.; SANTOS, D. R.; FREIRE, A. L. O.; SILVA, R. B. Estresse salino no crescimento inicial e nutrição mineral de Gliricídia (Gliricidia sepium (Jacq.) Kunt ex Steud) em solução nutritiva. Revista Brasileira de Ciência do Solo, v. 33, p. 1499-1505, 2009.
FERREIRA, P. A.; MOURA, R. F. de; SANTOS, D. B. dos; FONTES, P. C. R.; MELO, R. F. de. Efeitos da lixiviação e salinidade da água sobre um solo salinizado cultivado com beterraba. Revista Brasileira de Engenharia Agrícola e Ambiental, v.10, n.3, p. 570-578, 2006.

FREIRE, M. G. S.; SOUZA, E. R.; FREIRE, F. J. Fitorremediação de solos afetados por sais. In: Gheyi, H. R.; Dias, N. S.; Lacerda, C.F. Manejo da salinidade na agricultura. Fortaleza, INCT Sal, 2010. 472 p.

FREITAS, E. V. S.; FERNANDES, J. G.; CAMPOS, M. C. C.; FREIRE, M. B. G. dos $\mathrm{S}$. Alterações nos atributos físicos e químicos de dois solos submetidos à irrigação com água salina. Revista de Biologia e Ciências da Terra, v. 7, n. 1, p. 21-28, 2007.

GARCIA, G de O.; MARTINS FILHO, S.; REIS, E. F. dos; MORAES, W. B.; NAZÁRIO, A. de A. Alterações químicas de dois solos irrigados com água salina. Rev. Ciên. Agron., v. 39, n. 01, p. 7-18, 2008.

GONÇALVES, I. V. C.; FREIRE, M. B. G. dos S.; SANTOS, M. A. dos; SANTOS, E. R. dos; FREIRE, F. J. Alterações químicas de um Neossolo Flúvico irrigado com águas salinas. Revista Ciência Agronômica, v. 42, n. 3, p. 589-596, 2011.

HOLANDA FILHO, R. S. F. de; SANTOS, D. B. dos; AZEVEDO, C. A. V. de; COELHO, E. F.; LIMA, V. L. A. de. Água salina nos atributos químicos do solo e no estado nutricional da mandioqueira. Revista Brasileira de Engenharia Agrícola e Ambiental,v.15, n.1, p.60-66, 2011.

KELLER, J.; KARMELI, D. Trikler irrigation desing. Glendora: Rain Bird Sprinkler Manufacturing, 1975. 182 p.

MUNNS, R.; HUSAIN, S.; RIVELLI, A. R.; JAMES, R. A.; CONDON, A. G.; LINDSAY, M. P.; LAGUDAH, E. S.; SCHACHTMAN, D. P.; HARE, R. A. 
Avenues for increasing salt tolerance of crops, and the role of physiologically based selection traits. Plant and Soil, v. 247, p. 93$105,2002$.

NASCIMENTO, J. T.; PEDROSA, M. B.; TAVARES SOBRINHO, J. Efeito da variação de níveis de água disponível no solo sobre o crescimento e produção de feijão-caupi, vagens e grãos verdes. Horticultura Brasileira, v. 22, n. 2, p. 174177, 2004.

PEDROTTI, A.; CHAGAS, R. M.; RAMOS, V. C.; PRATA, A. P. do N.; LUCAS, A. A. T.; SANTOS, P. B. dos. Causas e consequências do processo de salinização dos solos. Revista Eletrônica em Gestão, Educação e Tecnologia Ambiental, $\quad$ v. 19, n. 2, p. 1308-1324, 2015.

PRAZERES, S. da S.; LACERDA, C. F. de; BARBOSA, F. E. L.; AMORIM, A. V.; ARAUJO, I., C. da S.; CAVALCANTE, L. F. Crescimento e trocas gasosas de plantas de feijão-caupi sob irrigação salina e doses de potássio. RevistaAgro@mbiente, v. 9, n. 2, p. 111-118, 2015.

RAMOS, H. M. M.; BASTOS, E. A.; CARDOSO, M. J.; RIBEIRO, V. Q.; NASCIMENTO, F. N. do. Produtividade de grãos verdes do feijão-caupi sob diferentes regimes hídricos. Eng. Agríc., v.34, n.4, 2014.

RHOADES, J. D.; KANDIAH, A.; MASHALI, A. M. Uso de águas salinas para produção agrícola. Campina Grande: UFPB, 2000. 117p. (Estudos FAO. Irrigação e drenagem, 48).

SILVA, A. O. da; KLAR, A. E.; SILVA, E. F. de F. e. Produção da cultura da beterraba irrigada com água salina. Engenharia na agricultura, v.21, n.3, p. 271-279, 2013.

SILVA, F. L. B.; LACERDA, C. F.; SOUSA, G. G.; NEVES, A. L. R.; SILVA, G. L.; SOUSA, C. H. C. Interação entre salinidade e biofertilizante bovino na cultura do feijãocaupi. Revista Brasileira de Engenharia Agrícola e Ambiental, v. 15, n. 4, p.383-389, 2011.

SNYDER RL. Equation for evaporation pan to evapotranspiration conversions. Journal of Irrigation and Drainage Engineering, v.118, p. 977-980, 1992.

SOUSA, M. S. M.; BEZERRA, F. M. L.; TEÓFILO, E. M. Coeficientes de cultura do feijão caupi na região litorânea do Ceará. Irriga, v. 10, n. 03, p. 241-248, 2005. 